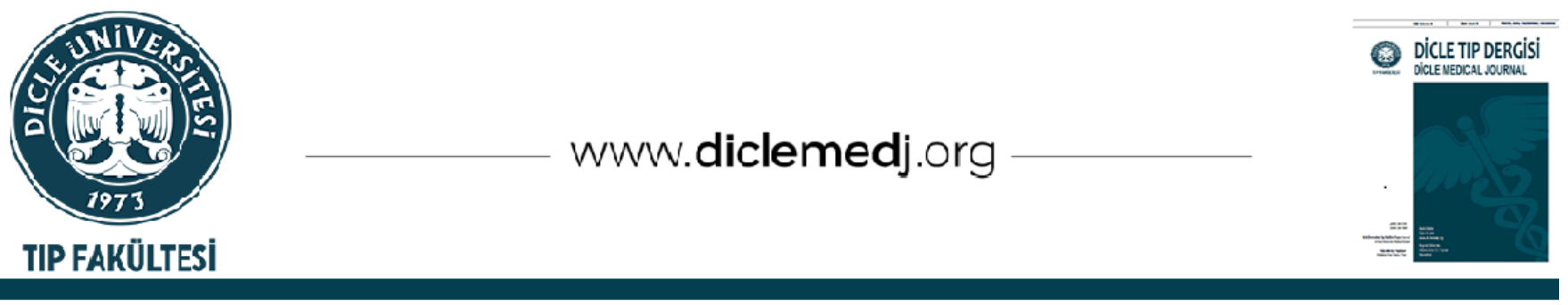

\title{
Tükürük Bezi Tümörü Tanısında Ultrasonografi (USG), Mangnetik Rezonans Görüntüleme (MRG), Bilgisayarlı Tomografi (BT), İnce İğne Aspirasyon Biyopsisi'nin (İ̈AB) Karşılaştırılması
}

\author{
Ahmet Doblan ${ }^{D_{1}}$, Ergün Sevil ${ }^{D_{2}}$, Togay Müderris ${ }^{D_{3}}$, Muzaffer Kırıș ${ }_{4}$ \\ 1 SBÜ Mehmet Akif Inan Eğitim ve Araştırma Hastanesi, KBB, Sanlıurfa, Türkiye \\ 2 Trabzon Kanuni Eğitim ve Araştırma Hastanesi, KBB, Trabzon, Türkiye \\ 3 İzmir Bakırçay Üniversitesi, KBB, Izmir, Türkiye \\ 4 Yıldırım Beyazıt Üniversitesi, KBB, Anakara, Türkiye
}

Geliș: 21.10.2020; Revizyon: 25.11.2020; Kabul Tarihi: 30.11.2020

Öz

Giriş: Tükürük bezleri tümörlerinde benign ve malign neoplazm arasındaki preoperatif farklılıkların belirlenmesi cerrahi operasyonun gerekliliği, aciliyeti ve kapsamını belirlemede önemlidir. Çalışmanın amacı, tükürük bezi kitlesi nedeniyle opere olmuş hastalarda, tükürük bezi tümörlerinin tanımlayıcı özelliklerinin ve tanı yöntemlerinin tanısal değerlerinin belirlenmesidir.

Yöntemler: Çalışma, 2008-2016 yılları arasında, tükürük bezinde malign veya benign kitle nedeni ile opere edilen hastaların, tıbbi kayıtlarının retrospektif incelenmesi ile yapılan tanımlayıcı tipte bir araştırmadır. Hastalara preoperatif dönemde yapılan Ultrasonografi (USG), Magnetik Rezonans Görüntüleme (MRG), Bilgisayarlı Tomografi (BT), İnce İğne Aspirasyon Biyopsisi'nin (İİA) sonuçları ve postoperatif dönemde histopatolojik tetkik sonuçları değerlendirildi. Kullanılan tanı yöntemlerinin sensitivite, spesifite, pozitif prediktif değer (PPD), negatif prediktif değer (NPD), eğri altında kalan alan (AUC \pm SE) değerlerinin hesaplanması için ROC analizi yapıldı.

Bulgular: Çalışma grubu 114 kişiden oluşmakta olup yaş ortalamaları 46.90ะ14.32 yıl idi. Çalışma grubunun \%54.4'ü erkek, \%71.9'u 40 yaşın üstündeydi. Tükürük bezi tümörlerinin \%71.9'u parotiste idi. Hastaların tanı amaçlı yapılan histopatoloji incelemesinde \% 11.4'ünün malign tümöre sahip olduğu bulundu. Hastalarda en sık rastlanan benign tümör çeşidi pleomorfik adenom, en sık rastlanan malign tümör çeşidi mukoepidermoid kanser olarak saptandı. Sensitivite, NPD, AUC \pm SE değerlerinin en yüksek olduğu yöntem MRG, spesifite ve PPD değerlerinin en yüksek olduğu yöntem İİAB idi.

Sonuç ve Öneriler: Sonuç olarak, hastalarda tükürük bezi tümörlerinin en sık parotis bezinde (\%11.4'ü malign) görüldüğü, en sık benign tükürük bezi tümörünün pleomorfik adenom, en sık malign tükürük bezi tümörünün mukoepidermoid kanser olduğu bulundu. Sensitivite, NPD, AUC \pm SE değeri en yüksek olan yöntem MRG ve spesifite ve PPD değeri en yüksek olan yöntem İIAB idi. USG, BT, MRG, İIAB’nin tükürük bezi tümörlerindeki tanısal değerlerini inceleyen, daha geniş örneklemlerde yapılacak klinik araştırmaların faydalı olacağı düşünüldü.

Anahtar kelimeler: Tükürük Bezi Neoplazileri, Ultrasonografi, Magnetik Rezonans Görüntüleme, Bilgisayarlı Tomografi, İnce İğne Aaspirasyon Biyopsisi

\section{DOI: 10.5798/dicletip.850494}

Correspondence / Yazışma Adresi: Ahmet Doblan, SBÜ Mehmet Akif İnan Eğitim ve Araştırma Hastanesi, Şanlıurfa, Türkiye e-mail: ahmetdoblan@yahoo.com 


\title{
Comparison of Ultrasonography (USG), Mangnetic Resonance Imaging (MRI), Computed Tomography (CT) and Fine Needle Aspiration Biopsy (FNAB) for the Diagnosis of Salivary Gland Tumor
}

\begin{abstract}
Objective: The determination of preoperative differences between benign and malignant neoplasms in salivary gland tumors is important in determining the necessity, urgency and scope of surgical operation. The aim of this study was to determine the descriptive characteristics of salivary gland tumors and the diagnostic value of diagnostic methods in patients operated for salivary gland mass.

Methods: The study is a descriptive study performed retrospectively with the medical records of patients operated for malignant or benign mass in salivary glands between 2008-2016. Preoperative Ultrasonography (US), Magnetic Resonance Imaging, Computed Tomography (CT), Fine Needle Aspiration Biopsy (FNAB) and postoperative histopathological results were evaluated. Sensitivity, specificity, positive predictive value (PPV), negative predictive value (NPV) calculations were used for the used diagnostic methods and each was expressed as a percentage (\%). Sensitivity, specificity, positive predictive value (PPD), negative predictive value (NPD), area under the curve \pm standard error (AUC \pm SE) values of the diagnostic methods were used for ROC analysis.

Results: The study group consisted of 114 individuals with a mean age of $46.90 \pm 14.32$ years. The most common localization of salivary gland tumors was parotid gland (71.9\%). Histopathological examination of the patients for diagnostic purposes revealed that $11.4 \%$ had malignant tumors. Pleomorphic adenoma was the most common benign tumor and mucoepidermoid cancer was the most common malignant tumor. The highest sensitivity, NPD, AUC \pm SE values were MRI and the method with the highest specificity and PPD was FNAB.

Conclusion: In conclusion, it was found that salivary gland tumors were most commonly seen in the parotid gland (11.4\% malignant), the most common benign salivary gland tumor was pleomorphic adenoma and the most common malignant salivary gland tumor was mucoepidermoid cancer. The method with the highest sensitivity, NPD, AUC \pm SE values was MRI and the method with the highest specificity and PPD was FNAB. It was thought that clinical studies in larger samples that examined the diagnostic values of USG, CT, MRI, FNAB in salivary gland tumors would be beneficial.
\end{abstract}

Keywords: Salivary Gland Neoplasms, Parotid Gland, Ultrasonography, Magnetic Resonance Imaging, Computed Tomography, Fine-Needle Aspiration Biopsy.

\section{GİRIŞ}

Tükürük bezleri tümörleri oral ve maksillofasiyal bölgelere özgüdür ve tüm baş ve boyun malignitelerinin yaklaşık \%3-5'ini oluşturur ${ }^{1}$. Tükürük bezi tümörleri nadir görülür, yıllık insidansı dünyanın farklı bölgelerinde $\quad 100.000$ 'de $\quad 0.5-2$ arasinda değişmektedir².

Üç büyük tükürük bezine ek olarak (parotis, submandibular ve sublingual) binlerce küçük tükürük bezi vardır³. Tükürük bezi tümörlerinin \%80'i parotis bezlerinde görülür ve tükürük bezi neoplazmalarının yaklaşık $\% 20$ 'si maligndir. Klinik pratikte genel bir kural olarak, tükürük bezi küçüldükçe, tümörün malign olma olasılığı artmaktadır. Parotis bezi tümörlerinin \%20-25'i, submandibular bezlerde \%40'ı, sublingual bezlerde \%90'ından fazlası maligndir ${ }^{2}$. Histolojik olarak en sik görülen benign tükürük bezi tümörü pleomorfik adenom, en sık görülen malign tükürük bezi tümörü mukopidermoid karsinomdur ${ }^{3,4}$.

\begin{tabular}{llr} 
Tükürük bezi & \multicolumn{2}{c}{ neoplazmalarının } \\
değerlendirilmesi & ve tanısı & klinik \\
değerlendirme, ve & Ultrasonografi & (USG), \\
Magnetik Rezonans & Görüntüleme & (MRG),
\end{tabular} Bilgisayarlı Tomografi (BT) gibi görüntüleme yöntemlerini ve İnce İğne Aspirasyon Biyopsisi'ni (İIAB) içerir. Ancak, kesin tanı kitlenin cerrahi eksizyonundan sonra koyulabilmektedir ${ }^{3}$. Yüzeyel yerleşimli tümörlerin değerlendirilmesinde ilk tercih edilen yöntem olan USG, bir kitlenin varlığını, yaygınlığını, vaskülaritesini, katı veya kistik bileşenleri değerlendirmek, İIAB'yi yönlendirebilmek için kullanılmaktadır. Diğer görüntüleme yöntemleriyle karşılaştırıldığında ucuzdur ve hasta için düşük risklidir ancak anatomik detaydan yoksundur ve çene kemikleri tarafından gizlenen derin lop kitleleri hakkında bilgi vermemektedir ${ }^{3}$. Yumuşak doku 
yayılımı ve perinöral sinir invazyonunu tanımlayan en hassas görüntüleme yöntemi olan MRG, malign ve benign tükürük bezi tümörlerinin ayırt edilmesinde, küçük ve derinde yer alan tümörleri saptamada kullanılmaktadır2,5. BT, tükürük bezinde, kanal veya kanaliküllerin kalsifikasyonlarını, kortikal kemik tutulumunu, eşzamanlı sialolityazis varlığını ve tümörünü temizlemek için mastoidektominin gerekli olup olmadığını belirlemede ve enflamatuar hastalığın neoplazmlardan ayırt edilmesinde faydalıdır. İIAB ise tanıda sıklıkla kullanılan, güvenli, hızlı ve uygun maliyetli bir yöntemdir. Temel olarak neoplastik ve nonneoplastik kitleleri birbirinden ayırmada, neoplastik kitlelerde malign ve benign ayrımının yapılmasında ve preoperatif dönemde cerrahi planlamada yardımcı olmaktadır ${ }^{2,3}$.

Benign ve malign neoplazmlar arasındaki farklılıkların belirlenmesi cerrahi operasyonun gerekliliği, aciliyeti ve kapsamını belirlemede çok önemlidir ${ }^{6}$. Literatürde, bunun için kullanılan tanı yöntemlerin hepsinin bir arada değerlendirildiği çalışma sayısı sınırlıdır.

Çalışmanın amacı, tükürük bezi kitlesi nedeniyle opere olmuş hastalarda tükürük bezi tümörlerinin tanımlayıcı özelliklerinin ve kullanılan tanı yöntemlerinden USG, MRG, BT ve İIAB'nin tanısal değerlerinin belirlenmesidir.

\section{YÖNTEMLER}

Çalışma, 2008-2016 yılları arasında, Kulak Burun Boğaz Polikliniği'nde tükürük bezinde kitle nedeni ile opere edilen hastaların sonrasında tıbbi kayıtlarının retrospektif incelenmesi ile yapılan tanımlayıcı tipte bir araştırmadır. Çalışma için harran üniversitesi klinik araştırmalar etik kurulundan 30.12.2019 tarih ve HRÜ.19.08.07 sayılı etik kurul onayı alınmıștır.

\section{Çalışma Grubunun Belirlenmesi}

Hastaların kayıtları incelenirken benign veya malign tükürük bezi neoplazmı nedeniyle takip edilmiş ve sonrasında opere edilmiş hastalar çalışmaya dahil edildi. Araştırmada kullanılacak tanı tetkiklerinden herhangi birinde veya daha fazlasında eksikleri olan hastalar çalışma grubuna dahil edilmedi. Sonuç olarak araştırma için tetkikleri incelenen hastalardan 24 tanesi, preoperatif tetkiklerinde eksiklikler olması nedeni ile çalışmaya dışı bırakıldı ve 114 hasta çalışma grubunu oluşturdu.

Çalışmanın yapılabilmesi için gerekli izinler ve etik kurul onayı alındı.

\section{İncelenen Tetkikler}

Hastalara preoperatif dönemde yapılan USG, MRG, BT, İIAB tetkiklerinin sonuçları ve postoperatif dönemde histopatolojik tetkik sonuçları değerlendirildi. İİAB dışındaki tetkiklerinden bazıları başka merkezde yapılmış ve tarafımıza yönlendirilmiş hastaların tetkikleri de araştırmaya dahil edildi. Kliniğimize tükürük bezi kitlesiyle başvuran hastaların tetkiklerinin tekrarı gerekli görülürse tekrar yapılmakta ve kurumumuzda yapılan her tetkik Radyoloji Anabilim Dalı'nda baş-boyun görüntülemesinde uzmanlaşmış hekimlerce değerlendirilmektedir. Kliniğimize tükürük bezi kitlesi nedeni ile başvuran hastaların hepsine İIAB yapılmaktadır. Sitolojik incelemesi, non-diagnostik olarak raporlanan hastaların onamı alınarak biyopsisi tekrarlanmaktadır. Toplamda 3 kez nondiagnostik olarak raporlanan hastalar için patolojik tanı olmadan cerrahi operasyon kararı verilmektedir. Hastaların İIAB incelemeleri kliniğimizdeki deneyimli hekimler tarafından yapıldı. İlk alınan İ̇AB incelemesinde tanı konulamaması durumunda veya lezyonu 1 cm'nin altında olan hastalarda İIAB, USG eşliğinde Radyoloji Anabilim Dalı Girişimsel Radyoloji Birimi'nde yapılmaktadır. İIAB lokal anestezi kullanmaksızın, 22 kalibrelik iğne ve 20 cc'lik tek kullanımlık enjektörler kullanılarak 
yapılmaktadır. Aspirasyon sonrasında aspirasyon materyali enjektöre çekilen hava ile beraber bir lama püskürtülmekte, diğer lam ile 45 derecelik açı sağlanarak, en az 3 yayma preparatı hazırlanmaktadır. Yaymalar alkol ile fikse edilerek ve Papanicolea yöntemi ile boyanmaktadır. Tüm sitolojik incelemeler sitopatoloji konusunda deneyimli olan patolog tarafindan incelenip, raporları hazırlanmaktadır.

\section{İstatistiksel Analizler}

Verilerin değerlendirilmesinde SPSS( Statistical Package for Social Sciences) 15 paket programı kullanıldı. Tanımlayıcı verilerin değerlendirilmesinde sayı, yüzde, ortalama ve standart sapma değerleri kullanıldı. Kullanılmıș tanı yöntemleri için sensitivite, spesifite, pozitif prediktif değer (PPD), negatif prediktif değer (NPD) hesaplamaları yapıldı ve her biri yüzde (\%) olarak ifade edildi.

\section{BULGULAR}

Çalışma grubu 114 kişiden oluşmakta olup yaş ortalamaları $46.90 \pm 14.32$ yıl idi. Çalışma grubunun 62'si (\%54.4) erkek, 82'si (\%71.9) 40 yaşın üstündeydi. Çalışma grubunun yaş grubu ve cinsiyete göre dağılımı Tablo 1'de verildi.

Tablo I: Çalışma grubunun yaş grubu ve cinsiyete göre dağılımı

\begin{tabular}{|ll|}
\hline \multicolumn{1}{|c|}{$\mathbf{n ( \% )}$} \\
\hline Cinsiyet & $62(54,4)$ \\
\hline Erkek & $52(45,6)$ \\
\hline Kadın & \\
\hline Yaş grubu & $32(28,1)$ \\
\hline$\leq 40$ yaş & $82(71,9)$ \\
\hline$>40$ yaş & $114(100)$ \\
\hline Toplam
\end{tabular}

Hastaların 82 'sinin $(\% 71,9)$ tükürük bezi kitlesi parotiste kitle iken, 32'sinin $\quad(\% 28,1)$ submandibuler bezde idi. Çalışma grubunun 59'unda $(\% 51,8)$ kitle sağ tarafa lateralize, 55 'inde $(\% 48,2)$ sol tarafa lateralize idi.
Hastaların tükürük bezi kitlesinin lokalizasyon ve lateralizasyon özellikleri Tablo 2'de verildi.

Tablo II: Hastaların tükürük bezi kitlesinin lokalizasyon ve lateralizasyon özellikleri

\begin{tabular}{|ll|}
\hline \multicolumn{1}{|c|}{ n(\%) } \\
\hline Kitlenin lokalizasyonu \\
\hline Parotiste kitle & $82(71,9)$ \\
\hline Submandibuler kitle & $32(28,1)$ \\
\hline Kitle lateralizasyonu & \\
\hline Sağ & $59(51,8)$ \\
\hline Sol & $55(48,2)$ \\
\hline Toplam & $114(100,0)$ \\
\hline
\end{tabular}

Tükürük bezi kitlesi bulunan hastaların 79'unda yüzeyel paratroidektomi, 31'ine submandibüler bez eksizyonu ve 4'üne total paratroidektomi tedavisi uygulanmıștır. Operasyon sonrası hastaların 46'sı $(\% 40,4)$ hastanede 2 gün ve daha az yatarak tedavi edilirken, 68'i $(\% 59,6)$ hastanede 2 günden fazla yatmıştır. Hastaların aldıkları tedaviyle ilgili özelliklerine göre dağılımı Tablo 3'te verildi.

Tablo III: Hastaların aldıkları tedavilerin özelliklerine göre dağılımı

\begin{tabular}{|ll|}
\hline \multicolumn{2}{|l|}{$\mathbf{n ( \% )}$} \\
\hline Tedavi için uygulanan cerrahi yöntem \\
\hline Submandibuler bez eksizyonu \\
\hline Total paratroidektomi & $79(69,3)$ \\
\hline Hastanede yatış süresi & $31(27,2)$ \\
\hline$\leq 2$ gün & $4(3,5)$ \\
\hline$>2$ gün & $46(40,4)$ \\
\hline Toplam & $68(59,6)$ \\
\hline
\end{tabular}

Tükürük bezi kitlesi nedeniyle opere edilen hastaların tanı amaçlı yapılan histopatoloji sonucu \%11,4'ünün, USG sonucu \%15,8'inin, MRG sonucu \%18,4'ünün, BT sonucu $\% 13,2$ 'sinin, İ̇AB sonucu \%9,6'sinın maligniteye sahip olduğu saptandı. Hastalara uygulanan tanı yöntemlerinin tanı (malign ve benign) oranları Tablo 4'te verildi. 
Tablo IV: Hastalara uygulanan tanı yöntemlerinin tanı (malign ve benign) oranları

\begin{tabular}{|lll|}
\hline Uygulanan yöntem & $\begin{array}{l}\text { Malign } \\
\mathbf{n}(\%)\end{array}$ & $\begin{array}{l}\text { Benign } \\
\mathbf{n}(\%)\end{array}$ \\
\hline Patoloji & $13(11,4)$ & $101(88,6)$ \\
\hline USG & $18(15,8)$ & $96(84,2)$ \\
\hline MRG & $21(18,4)$ & $93(81,6)$ \\
\hline BT & $15(13,2)$ & $99(86,8)$ \\
\hline İ̇B & $11(9,6)$ & $103(90,4)$ \\
\hline
\end{tabular}

Histopatolojik inceleme sonucunda, hastalarda en sık rastlanan üç benign tümör çeşidi pleomorfik adenom, Whartin tümörü, ranula tümörü idi. Malign tümörlerden en sı rastlananlar ise mukoepidermoid kanser, adenokistik kanser ve asinik hücreli tümör olarak bulundu. Tükürük bezi tümörlerinin histopatolojik tanı sonuçlarına göre dağılımı Tablo 5'te verildi.

Çalışmada incelenen tanı yöntemleri arasında sensitivite, NPD, AUC \pm SE değerlerinin en yüksek olduğu yöntem MRG, spesifite ve PPD değerlerinin en yüksek olduğu yöntem İ̇AB olarak bulundu. Tükürük bezi tümörlerini saptamada tanı yöntemlerinin tanısal değerleri Tablo 6 ve ROC analizi sonucu elde edilen grafik, Şekil 1'de verildi.
Tablo V: Tükürük bezi tümörlerinin histopatolojik tanı sonuçlarına göre dağılımı

\begin{tabular}{|ll|}
\hline Benign tümörler & $\mathrm{n}(\%)$ \\
\hline Pleomorfik adenom (PA) & $62(61,4)$ \\
\hline Whartim tümörü (WT) & $16(15,8)$ \\
\hline Ranula tümörü & $6(5,9)$ \\
\hline Bazal hücreli adenom & $3(3,0)$ \\
\hline Kronik sialodenit & $3(3,0)$ \\
\hline Lipom & $3(3,0)$ \\
\hline Dermoid kist & $1(1,0)$ \\
\hline Enfeksiyöz LAP & $1(1,0)$ \\
\hline Otolitik parotis dokusu+LAP & $1(1,0)$ \\
\hline Plexiform Nörofibrom & $1(1,0)$ \\
\hline Schwanoma & $1(1,0)$ \\
\hline Siyalodenit & $1(1,0)$ \\
\hline Sialolityazis & $1(1,0)$ \\
\hline WT+PA & $1(1,0)$ \\
\hline Toplam & $101(100,0)$ \\
\hline Malign Tümörler & \\
\hline Mukoepidermoid kanser & $5(38,5)$ \\
\hline Adenokistik kanser & $4(30,8)$ \\
\hline Asinik hücreli tümör & $2(15,4)$ \\
\hline Maltoma & $1(7,7)$ \\
\hline Skuamoz hücreli kanser & $1(7,7)$ \\
\hline Toplam & $13(100,0)$ \\
\hline
\end{tabular}

Tablo VI: Tükürük bezi tümörlerini saptamada tanı yöntemlerinin tanısal değerleri

\begin{tabular}{|c|c|c|c|c|c|c|}
\hline & Sensitivite & Spesifite & PPD & NPD & $\mathrm{AUC}+\mathrm{CF}$ & \\
\hline & $\%(\% 95 \mathrm{GA})$ & $\%(\% 95 \mathrm{GA})$ & $\%(\% 95 \mathrm{GA})$ & $\%(\% 95 \mathrm{GA})$ & AUCIDL & P \\
\hline & 53,85 & 89,11 & 38,89 & 93,75 & & \\
\hline USG & $(25,13-80,78)$ & $(81,35-94,44)$ & $(23,09-57,43)$ & $(89,25-96,44)$ & $0.12 \pm 0.09$ & 0.01 \\
\hline $\mathrm{MDC}$ & 92.31 & 91,09 & 57,14 & 98,92 & זם0 יחת & 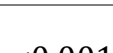 \\
\hline IVinu & $(63,97-99,81)$ & $(83,76-95,84)$ & $(41.21-71.72)$ & $(93,33-99,84)$ & $0.9< \pm 0.00$ & $<0.001$ \\
\hline RT & 61,54 & 93,07 & 53,33 & 94,95 & 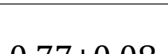 & 促 001 \\
\hline DI & $(31,58-86,14)$ & $(86,24-97,17)$ & $(33,17-72,46)$ & $(90,41-97,40)$ & $0.1+0.00$ & -0.001 \\
\hline İ்R & 76,92 & 99,01 & 90.91 & 97,09 & $00 ?+0,8$ & 00001 \\
\hline HID & $(46,19-94,96)$ & $(94,61-99,98)$ & $(58,17-98,63)$ & $(92,51-98,90)$ & $0.32=0.00$ & -0.001 \\
\hline
\end{tabular}

PPD: Pozitif prediktif değer, NPD: Negatif prediktif değer, AUC: Eğri altında kalan alan, SE: standart hata 


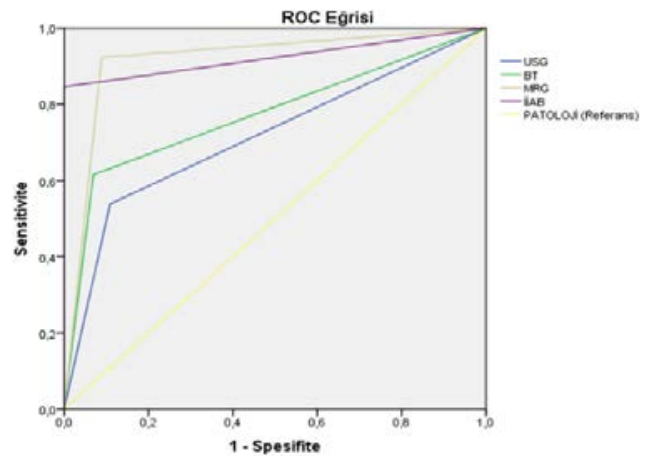

Şekil 1. Tükürük bezi tümörlerinde kullanılan tanı yöntemlerinin ROC eğrileri

\section{TARTIŞMA}

Tükürük bezi tümörleri, patolog veya cerrah için önemli teşhis ve yönetim zorlukları gösterebilecek, morfolojik ve klinik olarak çeşitlilik gösteren bir neoplazm grubudur6. Tükürük bezi tümörlerinde tedavi seçenekleri tümörün histolojik tipine bağlı olduğundan, benign tükürük bezi tümörlerinin malign olanlardan ayrılması, ameliyat öncesi tedavi planlaması için klinik olarak önemlidir7 ${ }^{7} \mathrm{Bu}$ durumda, tükürük bezi tümörlerinin özelliklerinin belirlenmesi ve tanısı için kullanılan görüntüleme yöntemleri önem kazanmaktadır.

Tükürük bezi tümörlerinden en sık etkilenen bezlerin, genellikle sirasıyla parotis ve submandibuler bezler olduğu bildirilmektedir ${ }^{8}$. Yapılan çeşitli araştırmaların sonuçları incelendiğinde tükürük bezi tümörlerinin en sık parotiste (\%70,0-91,1), ikinci olarak submandibüler bezde $(\% 8,3-24,0)$ olduğu bildirilmiştir ${ }^{9-12}$. Çalışma grubunda da benzer şekilde tükürük bezi tümörünün en sık görüldüğü tükürük bezinin parotis $(\% 71,9)$ ve ikinci olarak submandibuler bez $(\% 28,1)$ olduğu bulundu. Wang ve arkadaşlarının yaptıkları araştırmada ise tükürük bezi tümörlerinin en sık parotiste $(\% 69,8)$, ikinci olarak minör tükürük bezlerinde $(\% 19,0)$, üçüncü olarak submandibüler bezlerde $(\% 10,5)$ bulunduğu bildirilmiştir ${ }^{13}$.
Tükürük bezi tümörlerinin çoğunluğun benign karakterde olduğu bilinmektedir ${ }^{2}$. Çalışmada, tanı amaçlı yapılan histopatolojik inceleme sonucunda \%11,4 malign, \%88,6 benign tükürük bezi tümörü olduğu bulundu. Daha önce yapılmış çeşitli araştırmaların sonuçlarına göre tükürük bezi tümörlerinde malign tümör sıklığının \%19,4-35.1 arasında değiştiği, benign tükürük bezi tümörü sıklığının \%64,9-80.6 arasında değiştiği bildirilmektedir ${ }^{9,11-13 .}$

Hem majör hem de minör tükürük bezlerinde en sık görülen benign tümör tipi pleomorfik adenomdur. Malign tükürük bezi tümörleri içinde en yaygın olanı mukoepidermoid kanserdir ${ }^{2}$. Histopatolojik inceleme sonucunda, hastalarda en sık rastlanan benign tümör çeşidi pleomorfik adenom, en sik rastlanan malign tümör çeşidi ise mukoepidermoid kanser olarak bulundu. Yapılan başka araştırmalarda en sık benign tümör çeşidinin pleomorfik adenom, en sık malign tümör çeşidinin mukoepidermoid kanser olduğu bildirilmiştir 8,9,11-13. Vasconcelos ve arkadaşlarının yaptıkları araștırmaya göre en sık benign tükürük bezi tümörünün pleomorfik adenom, en sık malign tükürük bezi tümörünün adenoid kistik karsinom olduğu bildirilmiştir ${ }^{14}$. Tian ve arkadaşlarının yaptığı araştırmaya göre en sık benign tükürük bezi tümörü pleomorfik adenom (\%69) olarak bildirilirken en sık malign tükürük bezi tümörü mukoepidermoid kanser (\%30) ve adenoid kistik kanser (\%30) olarak bildirilmiştir ${ }^{15}$. Çalışmalar arasında, tükürük bezi tümörlerinin tanımlayıcı özellikleri arasında bazı farklılıklar olmasına, çalışma gruplarının yaş, cinsiyet, yaşam tarzı, coğrafik özellikler bakımından birbirinden farklı özelliklere sahip olması neden olmuş olabilir.

Tükürük bezi tümörleri yüzeysel lokalizasyonlarda olduğunda, bulunmaları genellikle kolaydır; ancak, tümör derin veya erken bir aşamada olduğunda, tanımlanması zor olabilir. Bu durumda USG, MRG, BT, IIIAB gibi 
bazı görüntüleme yöntemlerinin kullanılması gerekir ${ }^{16}$.

Çalışmada, tükürük bezi tümörlerinde, USG için sensitivite \%53,85 (25.13-80.78), spesifite \%89,11 (81.35-94.44), PPD \%38,89 (23.0957.43), NPD \%93,75 (89.25-96.44), AUC \pm SE $0.72 \pm 0.09$ bulundu. $\mathrm{Wu}$ ve arkadaşlarının araştırmasına göre USG'nin tükürük bezi tümörleri için sensitivite, spesifite, PPD, NPD değerleri sirasıyla \%38,9, \%90,1, \%29,2, \%93,3 olarak bildirilmiștir ${ }^{17}$. On dokuz araștırmanın incelendiği bir metaanalize göre USG'nin tükürün bezi tümörleri için sensitivitesinin \%63, spesifitesinin \%92, AUC değerinin 0.934 bulunduğu bildirilmiştir ${ }^{16}$. Kong ve arkadaşlarının yaptı̆̆ı metanalize göre USG'nin tükürük bezi tümörleri için sensitivitesi \%66, spesifitesi \%92, AUC'si 0.91 olarak rapor edilmiștir?

MR ve BT, tükürük bezi tümörlerinde tümörün tamamını ve bölgesel lenfadenopatiyi tanımlamak için idealdir. MRG yumuşak doku farklılaşmasını tanımlamada BT’ye göre üstündür. Yüksek çözünürlüklü teknikler kullanıldığında MRG derin doku yayılımı, kemik iliği infiltrasyonu, ödem, perinöral yayılım olup olmadığının tespitinde özellikle yararlıdır ${ }^{18}$.

Çalışmada, tükürük bezi tümörlerinde, MRG için sensitivite \%92,31 (63.97-99.81), spesifite \%91,09 (83.76-95.84), PPD \%57,14 (41.2171.72), NPD \%98,92 (93.33-99.84), AUC \pm SE $0.92 \pm 0.05$ bulundu. Çeşitli araştırmaların sonuçlarına göre MRG'nin tükürük bezi tümörleri için sensitivitesinin \%81-100, spesifitesinin \%63-97, PPD'sinin \%90-91.3, NPD'sinin \%97-100 arasında değiştiği bildirilmiştir ${ }^{19,20}$. Tükürük bezi tümörleriyle ilgili yapılan bir metaanalize göre MRG için sensitivite \%81, spesifite \%90, AUC 0.903 başka bir metaanalize göre sensitivite $\% 80$, spesifite \%90, AUC 0.92 olarak bildirilmiştir7,16.

Çalışmada, tükürük bezi tümörlerinde, BT için sensitivite \%61,54 (31.58-86.14), spesifite
\%93,07 (86.24-97.17), PPD \%53,33 (33.1772.46), NPD \%94.95 (90.41-97.40), AUC \pm SE $0.77 \pm 0.08$ bulundu. Bartels ve arkadaşlarının araştırmasında BT'nin tükürük bezi tümörleri için sensitivitesi \%100, spesifitesi \%42, Kim ve arkadaşlarının araștırmasında sırasıyla \%93 ve \%61 olarak bildirilmiştir. Liu ve arkadaşlarının yaptığı metaanalize göre BT’nin tükürük bezi tümörleri için sensitivitesi \%83, spesifitesi $\% 85$, AUC 0.912, başka bir metaanalize göre sensitivite $\% 70$, spesifite $\% 73$, AUC 0.77 olarak rapor edilmiştir 7,16 .

İİB minimal invaziv, ucuz ve erișilebilir bir tanı prosedürüdür. Tükürük bezi noneoplastik lezyonlarında, neoplastik olmayan lezyonların gereksiz cerrahi rezeksiyonunu önlemede ve neoplazmların tedavisinde, benign ve malign neoplazmaları yüksek hassasiyetle ayırt etmede yararlı bir araç olduğu kanıtlanmıştır6. Çalışmada, tükürük bezi tümörlerinde, İİAB için sensitivite \%76,92 (46.19-94.96), spesifite \%99,01 (94.61-99.98), PPD \%90,91 (58.1798,63), NPD \%97,09 (92.51-98.9), AUC \pm SE $0.92 \pm 0.06$ bulundu. Tükürük bezi tümörlerinde İIAB'nin etkinliğini araştıran çeşitli araştırmaların sonucuna göre sensitivite $\% 58,2-96,9$, spesifite \%70-100, PPD \%81.292.9, NPD \%92,6-98,4 olarak bildirilmiștir9,21-24. Schmidt ve arkadaşları tarafından yapılan bir metaanalize göre sensitivite $\% 80$, spesifite \%97, AUC 0.96 olarak rapor edilmiștir ${ }^{25}$.

\section{Sinirlılıklar}

Araştırmanın en önemli sınırlılığı retrospektif olarak yapılmasıdır. Prospektif tipte planlanacak bir klinik araştırma ile daha güçlü kanıtlar elde edilebilmektedir. İkinci sinırlılığımız, kullanılan tanı testlerinin hepsinin aynı merkezde benzer bir prosedür ile uygulanmamış olmasıdır. Araştırmanın yapıldığı merkez dıșında yapılmış tanı testleri de araştırmaya dahil edilmiştir. Her ne kadar dış merkezli tetkikler hastanemizde tekrar raporlanmış olsa da bu önemli bir dezavantaj oluşturmuştur. Bununla birlikte çalışma süresi 
yaklaşık 8 yıllık bir zaman dilimini kapsadığından aynı klinikte; ancak aynı doktorlar tarafından tetkik değerlendirilmesi yapılamamıştır. Farklı radyologlar, aynı vaka üzerinde farklı yorumlamalarda bulunabilir ve bu araştırmanın sonucu etkileyebilir. $\mathrm{Bu}$ nedenle dahil edilme kriterleri ve tanı ölçütleri standardize edilerek yapılacak klinik araştırmalar, daha güçlü kanıtlar elde edilmesini sağlayacaktır.

\section{SONUÇ VE ÖNERÍLER}

Sonuç olarak, hastalarda tükürük bezi tümörlerinin en sık parotis, ikinci olarak submandibüler bezde olduğu, bu kitlelerden $\% 11,4$ 'ünün malign karakterde olduğu, en slk benign tümörün pleomorfik adenom, en slk malign tümörün mukoepidermoid kanser olduğu ve USG, MRG, BT, İIAB'nin tükürük bezi tümörlerinin tanısında güvenilir yöntemler olduğu saptandı. USG, MRG, BT, İİAB'nin tümörü olmayan vakaları yakalama gücü yüksek iken, tümörü olan vakaları kaçırabilme ihtimali vardır ve bu nedenle tanı için tek başlarına kullanılmaları yeterli değildir.

USG, BT, MRG, İIAB'nin tükürük bezi tümörlerindeki tanısal değerlerini inceleyen, daha geniş örneklemlerde yapılacak klinik araştırmaların faydalı olacağı düşünüldü. Her bir tanı tekniğinin avantajları ve dezavantajları vardır. $\mathrm{Bu}$ nedenle, farklı görüntüleme tekniklerinin kombinasyon halinde kullanılmasının, güçlü yanları arttırabileceği, eksiklikleri azaltabileceği ve daha doğru bir teşhisin elde edilmesini sağlayarak tükürük bezi tümörlerinin yönetim sürecini iyileştireceği kanaatine varıldı.

Etik Kurul Onayı: Çalışma için harran üniversitesi klinik araştırmalar etik kurulundan 30.12.2019 tarih ve HRÜ.19.08.07 sayılı etik kurul onayı alınmıştır.

Çıkar Çatışması Beyanı: Yazarlar çıkar çatışması olmadığını bildirmişlerdir.
Finansal Destek: Bu çalışma herhangi bir fon tarafından desteklenmemiştir.

Declaration of Conflicting Interests: The authors declare that they have no conflict of interest.

Financial Disclosure: No financial support was received.

\section{KAYNAKLAR}

1. Mifsud MJ, Burton JN, Trotti AM, Padhya TA. Multidisciplinary management of salivary gland cancers. Cancer Control. 2016; 23: 242-8.

2. To VSH, Chan JYW, Tsang RK, Wei WI. Review of salivary gland neoplasms. ISRN otolaryngology. 2012; 2012.

3. Mayland EJ, Pou AM. Evaluation and diagnosis of salivary gland neoplasms. Operative Techniques in Otolaryngology-Head and Neck Surgery. 2018; 29: 129-34.

4. Özbay M, Şengül E, Topçu İ. Parotis kitlelerinde tanı ve cerrahi tedavi sonuçları. 2016; 43: 315-18.

5. Guzzo M, Locati LD, Prott FJ, et al. Major and minor salivary gland tumors. Critical reviews in oncology/hematology. 2010; 74: 134-48.

6. Farahani SJ, Baloch Z. Retrospective assessment of the effectiveness of the Milan system for reporting salivary gland cytology: A systematic review and meta-analysis of published literature. Diagnostic cytopathology. 2019; 47: 67-87.

7. Kong $\mathrm{X}, \mathrm{Li} \mathrm{H}, \mathrm{Han} \mathrm{Z}$. The diagnostic role of ultrasonography, computed tomography, magnetic resonance imaging, positron emission tomography/computed tomography, and real-time elastography in the differentiation between benign and malignant salivary gland tumors: a metaanalysis. Oral Surgery, Oral Medicine, Oral Pathology and Oral Radiology. 2019; 128: 431-43.

8. Araya J, Martinez R, Niklander S, Marshall M, Esguep A. Incidence and prevalence of salivary gland tumours in Valparaiso, Chile. Medicina oral, patologia oral y cirugia bucal. 2015; 20: e532.

9. Rajdeo RN, Shrivastava AC, Bajaj J, Shrikhande AV, Rajdeo RN. Clinicopathological study of salivary 
gland tumors: An observation in tertiary hospital of central India. Inter J Rese Med Sci. 2015; 3: 1691-6.

10. Song IH, Song JS, Sung CO, et al. Accuracy of core needle biopsy versus fine needle aspiration cytology for diagnosing salivary gland tumors. Journal of pathology and translational medicine. 2015; 49: 136.

11. Leelamma JP, Mohan BP. Spectrum of primary epithelial tumors of major salivary glands: a 5 year record based descriptive study from a tertiary care centre. Int J Adv Med. 2017; 4: 5627.

12. Wahiduzzaman M, Barman N, Rahman T, et al. Major Salivary gland tumors: A Clinicopathological study. Journal of Shaheed Suhrawardy Medical College. 2013; 5: 43-5.

13. Wang X-d, Meng L-j, Hou T-t, Huang S-h. Tumours of the salivary glands in northeastern China: a retrospective study of 2508 patients. British Journal of Oral and Maxillofacial Surgery. 2015; 53: 132-7.

14. Vasconcelos AC, Nör F, Meurer $L$ et al. Clinicopathological analysis of salivary gland tumors over a 15-year period. Brazilian oral research. 2016; 30.

15. Tian Z, Li L, Wang L, Hu Y, Li J. Salivary gland neoplasms in oral and maxillofacial regions: a 23year retrospective study of 6982 cases in an eastern Chinese population. International journal of oral and maxillofacial surgery. 2010; 39: 235-42.

16. Liu Y, Li J, Tan Y-r, Xiong P, Zhong L-p. Accuracy of diagnosis of salivary gland tumors with the use of ultrasonography, computed tomography, and magnetic resonance imaging: a meta-analysis. Oral surgery, oral medicine, oral pathology and oral radiology. 2015; 119: 238-45. e2.

17. Wu S, Liu G, Chen R, Guan Y. Role of ultrasound in the assessment of benignity and malignancy of parotid masses. Dentomaxillofacial Radiology. 2012; 41: 131-5.

18. Lee $\mathrm{Y}$, Wong $\mathrm{K}$, King A, Ahuja A. Imaging of salivary gland tumours. European journal of radiology. 2008; 66: 419-36.

19. Milad P, Elbegiermy M, Shokry T, et al. The added value of pretreatment DW MRI in characterization of salivary glands pathologies. American journal of otolaryngology. 2017; 38: 13-20.

20. Zheng N, Li R, Liu W, Shao S, Jiang S. The diagnostic value of combining conventional, diffusion-weighted imaging and dynamic contrastenhanced MRI for salivary gland tumors. The British journal of radiology. 2018; 91: 20170707.

21. Nguansangiam S, Jesdapatarakul S, Dhanarak N, Sosrisakorn K. Accuracy of fine needle aspiration cytology of salivary gland lesions: routine diagnostic experience in Bangkok, Thailand. Asian Pac J Cancer Prev. 2012; 13: 1583-8.

22. Tryggvason G, Gailey MP, Hulstein SL, et al. Accuracy of fine-needle aspiration and imaging in the preoperative workup of salivary gland mass lesions treated surgically. The Laryngoscope. 2013; 12: 158-63.

23. Jain R, Gupta R, Kudesia M, Singh S. Fine needle aspiration cytology in diagnosis of salivary gland lesions: A study with histologic comparison. Cytojournal. 2013; 10.

24. Singh A, Haritwal A, Murali B. Correlation between cytology and histopathology of the salivary glam. The Australasian medical journal. 2011; 4: 66.

25. Schmidt RL, Hall BJ, Wilson AR, Layfield LJ. A systematic review and meta-analysis of the diagnostic accuracy of fine-needle aspiration cytology for parotid gland lesions. American journal of clinical pathology. 2011; 136: 45-59. 